\title{
Cystic biliary atresia is different from choledochal cyst
}

\author{
Daniele Pariente $\cdot$ Stephanie Franchi-Abella
}

Received: 8 May 2009 / Accepted: 9 May 2009/Published online: 4 June 2009

(C) Springer-Verlag 2009

Sir,

We read with interest the article by Veigel et al. [1] titled "Fibropolycystic liver diseases in children". However, we disagree with the interpretation of Fig. 14. The authors show what they call "intraduodenal type III choledochal cyst (choledochocele) in a 2-month-old girl who presented with vomiting". They describe the "cholangiogram (that) shows cystic enlargement of the distal common bile duct to form a choledochocele" and "extravasated contrast material". In our opinion this cholangiogram represents a case of cystic biliary atresia with a large cyst on the remnant of the common bile duct, or what the authors call "biliary atresia associated with choledochal cyst" further in the article. This cyst communicates with the gallbladder that has been punctured for opacification, but does not communicate with the duodenum, indicating that there is atresia of the distal choledochus. What the authors call "extravasated contrast material", only seen in projection of the liver hilum, represents the "cloud-like" pattern of intrahepatic bile ducts characteristic of biliary atresia. This form of biliary atresia should be termed "cystic biliary atresia", and should not be confused with choledochal cyst [2].

To confirm our interpretation of the cholangiogram, it would be interesting to check the medical records of this baby girl and to search for discoloured stools and jaundice or biological signs of cholestasis at diagnosis. Fortunately, with surgical treatment this cystic variant of biliary atresia usually has a more favourable evolution than the other forms, particularly with early surgery.

\section{References}

1. Veigel MC, Prescott-Focht J, Rodriguez MG et al (2009) Fibropolycystic liver disease in children. Pediatr Radiol 39:317327

2. Caponcelli E, Knisely AS, Davenport M (2008) Cystic biliary atresia: an etiologic and prognostic subgroup. J Pediatr Surg 43:1619-1624

D. Pariente $(\bowtie) \cdot$ S. Franchi-Abella

Department of Radiology, Hospital de Bicetre,

78 rue de General Leclerc,

Le Kremlin Bicetre 94275, France

e-mail: daniele.pariente@bct.ap-hop-paris.fr 